\title{
Tapetes microbianos del Salar de Llamará, norte de Chile
}

\author{
Microbial mats from the Llamará salt flat, northern Chile \\ CECILIA DEMERGASSO ${ }^{1}$, GUILLERMO $\mathrm{CHONG}^{2}$, PEDRO GALLEGUILLOS ${ }^{1}$, \\ LORENA ESCUDERO ${ }^{1}$, MAIRA MARTÍNEZ-ALONSO ${ }^{3}$ \& ISABEL ESTEVE ${ }^{3}$ \\ ${ }^{1}$ Laboratorio de Microbiología Minera y ${ }^{2}$ Departamento de Ciencias Geológicas, \\ Universidad Católica del Norte, Avenida Angamos 0610, Antofagasta, Chile; \\ e-mail1: cdemerga@ucn.cl \\ ${ }^{3}$ Departamento de Genética y Microbiología, Universidad Autónoma de Barcelona, Bellaterra, España
}

\begin{abstract}
RESUMEN
Se estudiaron las comunidades estratificadas de microorganismos fotosintéticos que se encuentran en el Salar de Llamará ubicado en el desierto de Atacama, norte de Chile, mediante métodos microscópicos y espectrofotométricos. El espesor de la zona fótica de los tapetes descritos varió entre 8 y $30 \mathrm{~mm}$ lo cual podría atribuirse a la granulometría y la composición mineralógica de los sedimentos. Se diferencian tres tipos de tapetes. El primero con una única capa pigmentada de color verde; el segundo con capas de colores verde y naranja y un tercero en el que se observa, además de las capas verde y naranja, una de color púrpura. En uno de los sitios muestreados no se encontraron capas pigmentadas. Debajo de la zona pigmentada el sedimento es de color blanco, excepto en uno de los sectores donde se observó una coloración negra atribuible a sulfuro de hierro. Los microorganismos predominantes de la capa naranja fueron diatomeas y cianobacterias unicelulares principalmente de los grupos Cyanothece y Synechococcus. Las cianobacterias filamentosas Microccoleus sp. y Oscillatoria sp. fueron las más abundantes en la capa verde. No se observaron diatomeas en los sitios estudiados donde la salinidad del agua intersticial osciló entre 12 y $33 \%$. En la capa verde de estos sitios predominaron las cianobacterias cocoides, de los grupos Synechococcus, Cyanothece y Gloeocapsa y del género Gloeobacter, sobre las cianobacterias filamentosas. La capa púrpura estuvo compuesta principalmente por bacterias fototróficas anoxigénicas similares a células de los géneros Chromatium y Thiocapsa. Los espectros de absorción revelaron que la clorofila a es el pigmento más abundante en la mayoría de las muestras analizadas. Los valores integrados de clorofila a y bacterioclorofila a alcanzaron 230 y $144 \mathrm{mg} \mathrm{m}^{-2}$ en el espesor de la zona pigmentada, respectivamente. También se detectaron abundantes microorganismos no fotosintéticos en los tapetes incluyendo cocos y bacilos no identificados. En todos los tapetes muestreados en el Salar se encontraron bacterias reductoras de sulfato.
\end{abstract}

Palabras clave: Chile, tapetes microbianos, salares, desierto, bacterias fototróficas.

\begin{abstract}
Stratified photosynthetic microbial mats are described from the Salar de Llamará, a salt flat basin located in the Atacama desert of northern Chile. Microscopic and spectrophotometric techniques were used. The thickness of the photic zone of these communities spans 8 to $30 \mathrm{~mm}$. This is probably due to the grain size and mineralogical composition of associated sediments. Three different types of mats were recognized. A first one was characterized by a green pigmented layer; a second with orange and green coloured layers, and the third with orange and green layers and an additional purple layer. At one sampling site, no pigmented layers were present. Sediments underlying the mats were white, but in one site, black coloured sediments were observed; this dark colour is probably the result of iron sulphide precipitation. Predominant microorganisms in the orange pigmented layers were diatoms and unicellular cyanobacteria, mainly from the Cyanothece and Synechococcus groups. Filamentous cyanobacteria Microleus sp. and Oscillatoria sp. were the most abundant in the green layer. When interstitial brines reached salinities between 12 and $33 \%$, no diatoms were observed, and the coccoidal cyanobacteria from the Synechococcus, Cyanothece and Gloeocapsa groups and genus Gloeobacter predominated over filamentous Cyanobacteria in the green layer. The purple layer was built primarily of anoxygenic phototrophic bacteria similar to cells of the genera Chromatium and Thiocapsa. Absorption spectra revealed that chlorophyll a is the most abundant pigment in most of analyzed samples. Integrated values of chlorophyll a and bacteriochlorophyll a reached values of up to 230 and $144 \mathrm{mg} \mathrm{m}^{-2}$ along all of the pigmented zone, respectively. Abundant non-photosynthetic microorganisms were found in the mats, including unidentified cocci and bacilli. Sulphate reducing bacteria were present in all the sampled mats.
\end{abstract}

Key words: Chile, microbial mats, salt flats, desert, phototrophic bacteria. 


\section{INTRODUCCIÓN}

Los tapetes microbianos ("microbial mats") han sido descritos como comunidades bentónicas estratificadas que se desarrollan en la interfase entre el agua y sustratos sólidos. Estos requieren de un basamento donde establecerse, ya que se constituyen por la unión de los microorganismos a las partículas salinas y de sedimentos clásticos. La granulometría de los sedimentos es importante, dado que de esta depende el drenaje, incluyendo la capacidad de retención de agua y la aireación.

Frecuentemente, los tapetes microbianos son estructuras laminadas. El tipo de laminación está controlada por factores como la luz, la temperatura, la salinidad, el oxígeno disuelto y la presencia de sulfuros. Estas laminaciones tienen coloración diferenciada como resultado del desarrollo de bacterias fotosintéticas que contienen distintos pigmentos y, por lo tanto, distintos patrones de utilización de la luz disponible.

La presencia de estos tapetes está restringida a ambientes extremos que incluyen ambientes marinos costeros y ambientes hipersalinos (Bauld 1984, Van Gemerden et al. 1989), vertientes termales (Castenholz 1984, Jorgensen \& Nelson 1988) y lagos alcalinos (Brock 1978). En el sector andino entre los $14^{\circ}$ y $27^{\circ} \mathrm{S}$ se encuentran numerosos y variados depósitos salinos entre los que destacan las cuencas endorreicas de los lagos y los salares andinos. En el caso del sector chileno de la franja mencionada, los salares son muy variados y se extienden en todo su territorio desde, prácticamente, la zona litoral hasta la alta cordillera, incluyendo cuerpos salinos fosilizados en la parte occidental, hasta otros en plena evolución como sucede en la alta cordillera, con los correspondientes estados intermedios. Los salares se clasifican de acuerdo a su ubicación geográfica, aunque esto implica también importantes diferencias entre ellos. Esta división incluye, de oeste a este, a los salares de la cordillera de la Costa, de la Depresión Central, de la Depresión Preandina y a los salares y lagos andinos de la alta cordillera (Fig. 1) (Chong 1984).

El Salar de Llamará es uno de los depósitos salinos que se clasifica entre los salares de la Depresión Central (Chong 1984). La historia geológica de la cuenca se inicia en el Terciario Superior y su desarrollo actual corresponde a cuencas menores emplazadas sobre depósitos salinos más antiguos que incluyen una evolución lacustre. Estos ambientes han sido estudiados en tópicos específicos (Zúñiga et al. 1999) como su origen, geología, hidrogeología y aspectos geoquímicos (Chong 1984, Risacher \&
Fritz 1991a, 1991b), características paleobiológicas, limnología, población de invertebrados (Hurlbert et al. 1984, Alpers \& Whittemore 1990, Igarzábal 1991, Servant-Vildary \& Mello 1993, Grosjean 1994, López et al. 1999). Aunque en estos sistemas se han realizado investigaciones sobre la diversidad de microorganismos heterotróficos (Zúñiga et al. 1991, Prado et al. 1993), no se tiene información sobre los microorganismos fototróficos que los constituyen. Las bacterias fototróficas tanto oxigénicas como anoxigénicas juegan un papel relevante por tratarse de microorganismos productores primarios. Son además los principales colonizadores de los tapetes microbianos y, algunos de ellos, contribuyen activamente a dar estabilidad a los sedimentos.

El objetivo de este trabajo es caracterizar las comunidades que forman los tapetes microbianos que se encuentran en esta cuenca evaporítica por métodos microscópicos y espectrofotométricos e intentar discernir las variables que controlan la formación y estructura de estas comunidades laminadas. Su estudio se incluye en la investigación orientada a la búsqueda de microorganismos de importancia geomicrobiológica y biotecnológica, en el norte de Chile. Por otra parte, el conocimiento de la biodiversidad en estos frágiles sistemas, sumará antecedentes para su protección, dada la intensa explotación de los recursos hídricos en el desierto de Atacama.

\section{MATERIALES Y MÉTODOS}

\section{Descripción de los sitios de muestreo}

El Salar de Llamará está ubicado en el desierto de Atacama, norte de Chile, a una altitud aproximada de $800 \mathrm{~m}$ (Fig. 1). Sus coordenadas centrales son $21^{\circ} 23^{\prime} \mathrm{S}, 69^{\circ} 37^{\prime} \mathrm{O}$. Su historia sedimentaria es compleja, y se inicia como mínimo en el Mioceno Superior. Está asociada a la formación de cuerpos lacustres que han evolucionado a otros evaporíticos. Las comunidades bentónicas de microorganismos estratificadas que se describen en este trabajo, corresponden a un salar actual de esta cuenca.

$\mathrm{Su}$ superficie corresponde a una costra salina, seca, dura, de sulfatos y cloruros, de colores pardo-rojizos al estar teñida por sedimentos y blanca en los lugares donde está saturada de agua. Esta puede, ocasionalmente, quedar inundada en forma parcial por cuerpos de agua efímeros que redisuelven y reprecipitan sales, como en los casos de grandes precipitaciones en la estación estival producto del fenómeno meteorológico conocido como "invierno altiplánico". 


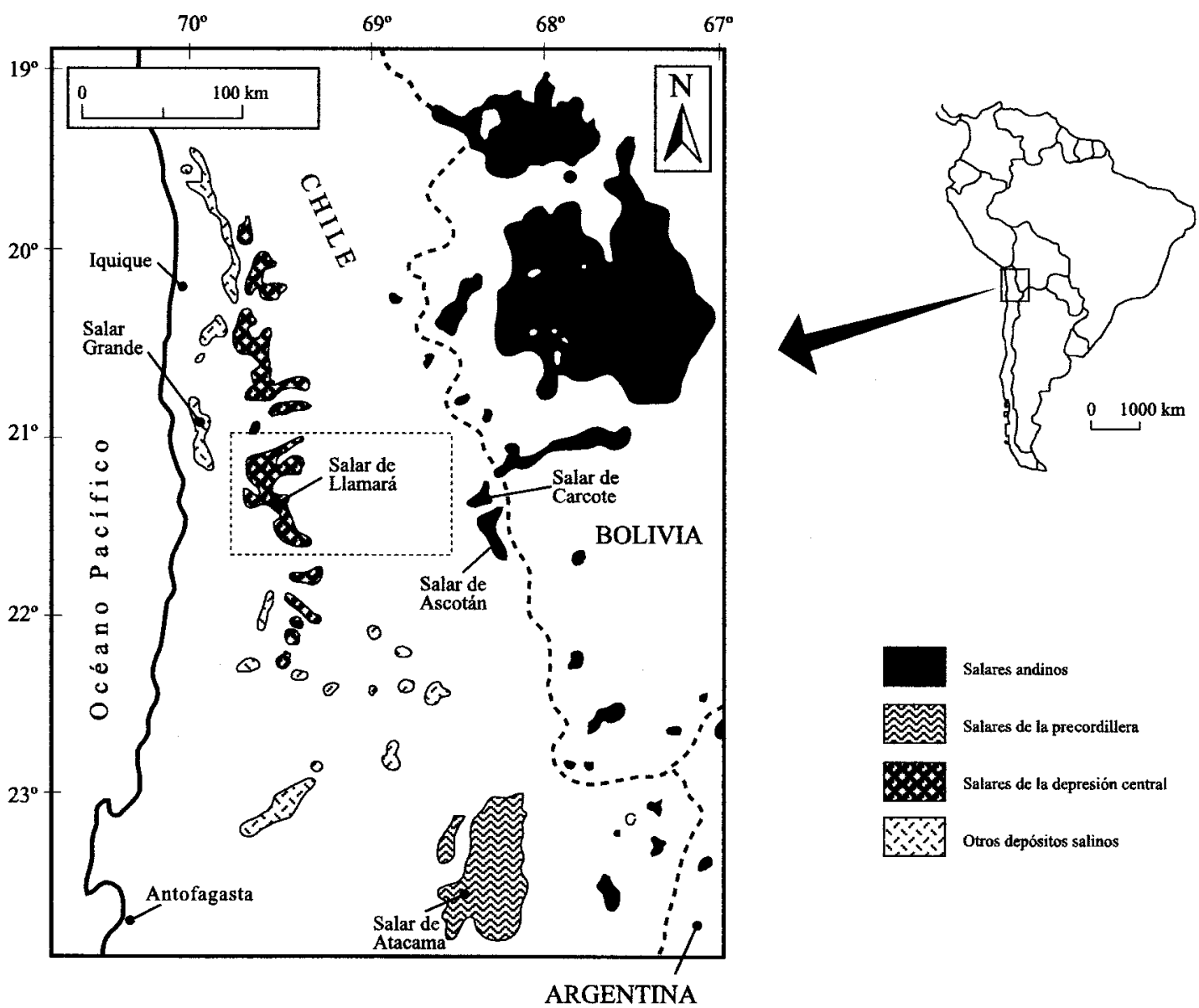

Fig. 1: Localización geográfica del Salar de Llamará (mapa modificado a partir del presentado por López et al. 1999).

Geographic location of the Salar de Llamará (modified after Lopez et al. 1999).

El nivel freático es somero y la disolución subsuperficial de sales genera estructuras de disolución y colapso, llamadas "sink-holes" conocidos localmente como "puquios". Estas estructuras tienen forma circular, con diámetros de hasta $100 \mathrm{~m}$, con lagunas de salmueras en sus partes más bajas, producto de la surgencia de las aguas subterráneas. La evaporación continua reduce el tamaño de las lagunas formando en sus bordes una aureola con costras blancas y saturadas en salmueras. El fondo de los puquios está tapizado de cristales de yeso. Estos cristales forman cuerpos circulares decimétricos que crecen sobre pequeñas superficies solevantadas.

Los tapetes se recolectaron en los Puquios de Huatacondo ubicados a unos $10 \mathrm{~km}$ al oeste de la Ruta 5 (Fig. 2) y se numeraron de manera arbitraria. Se escogieron cinco puntos de muestreo, sobre la base de la heterogeneidad del salar y las posibilidades de acceso. En el Puquio 2 o Central, el mayor, se recolectaron tres muestras y una en cada uno de los otros puquios. El que se estudió con más detalle fue el Sitio D (Fig. 2) que es donde se encontró el tapete más estructurado. Las muestras se tomaron en invierno de 1999 (julio) y en verano de 1998 y 1999 (diciembre).

Se cortaron secciones de aproximadamente $300 \mathrm{~cm}^{2}$ y $15 \mathrm{~cm}$ de profundidad, separando in situ las capas con diferente pigmentación. De cada una de las laminaciones separadas se tomaron diferentes alícuotas para la determinación de pigmentos y proteínas y la identificación y recuento de microorganismos. Las muestras para la identificación de microorganismos mediante microscopía óptica se fijaron en formaldehído $4 \%$ y con glutaraldehído $2,5 \%$ para la observación con microscopio electrónico de barrido.

Las muestras destinadas a la caracterización mineralógica de los sedimentos se recolectaron en testigos de PVC de $5 \mathrm{~cm}$ de diámetro y 


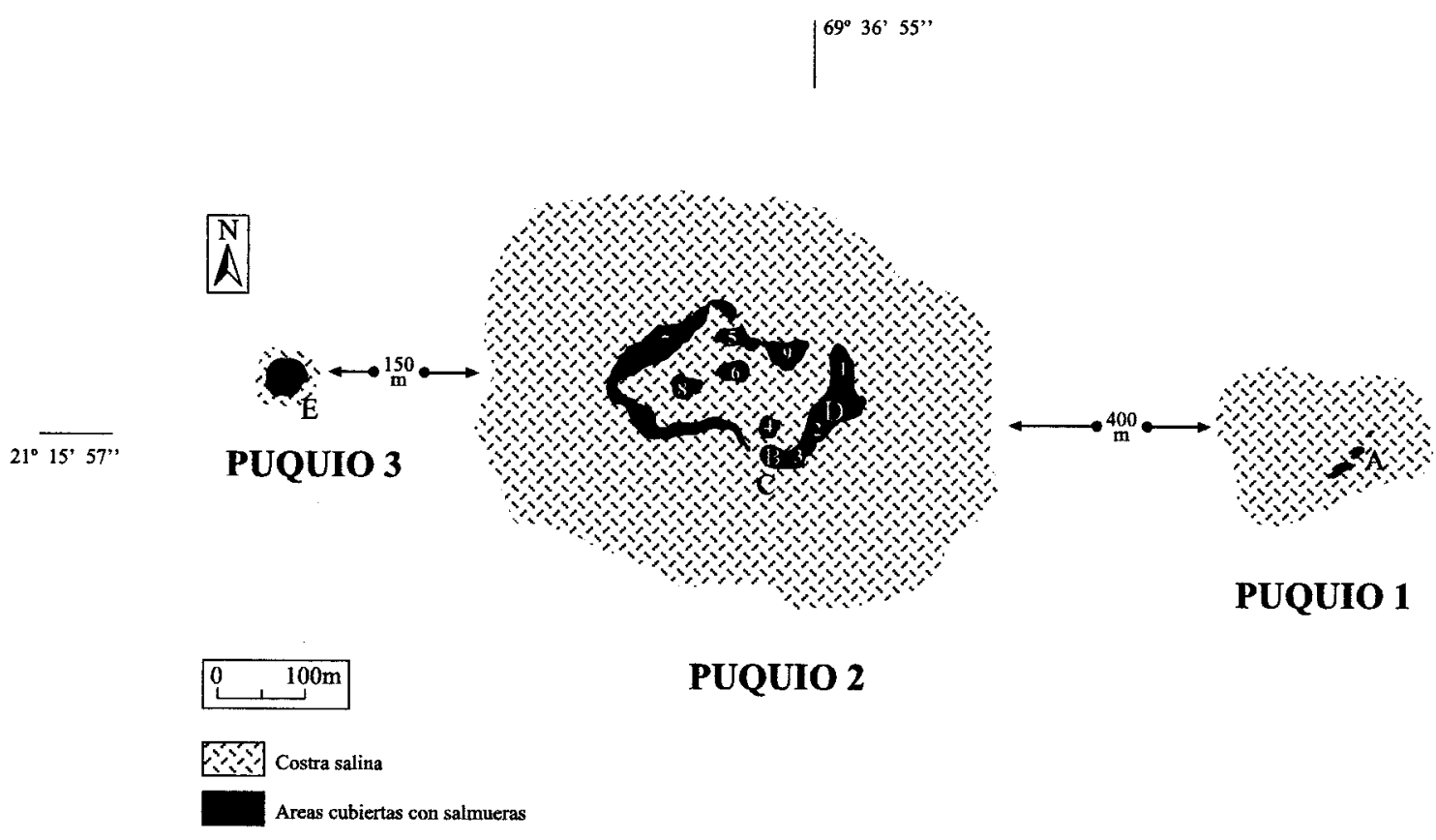

Fig. 2: Ubicación de Puquios y sitios muestreados (mapa modificado a partir del presentado por López et al. 1999).

Location of puquios and sampling stations (modified after Lopez et al. 1999).

$20 \mathrm{~cm}$ de largo. Todo el material muestreado se transportó, refrigerado, al laboratorio.

\section{Parámetros fisicoquímicos}

Se midieron in situ la temperatura, el $\mathrm{pH}$, la conductividad y la salinidad de las salmueras que cubría los tapetes microbianos muestreados. Todos los parámetros que se informan se midieron entre las 9:30 y las 13:00 h. Cuando los tapetes no estaban cubiertos por agua, los parámetros descritos fueron medidos, en el laboratorio, en el agua intersticial extraída de estos. Se usó un medidor de $\mathrm{pH} /$ concentración Orion, modelo 290 A, para la determinación de temperatura y $\mathrm{pH}$. La conductividad y salinidad se midieron con un conductivímetro Orion, modelo 115 .

\section{Microscopía}

Las muestras frescas y muestras fijadas con formaldehído $4 \%$, de cada capa, se observaron con microscopio de contraste de fases y con microscopio de epifluorescencia Leika DM/LS. Para la observación mediante microscopía electrónica de barrido se siguió el procedimiento descrito por Mir et al. (1991). La observación y toma de imágenes se realizó utilizando un equipo JEOL JSM T-300.

\section{Análisis de pigmentos y proteínas}

Las muestras utilizadas para estos análisis se preservaron a $-20{ }^{\circ} \mathrm{C}$ hasta su procesamiento. Los espectros de absorción se realizaron entre 200 y $900 \mathrm{~nm}$ en un espectrofotómetro UV-visible, Perkin Elmer Modelo Lambda 20. Para el cálculo simultáneo de clorofila a (Chl a), bacterioclorofila a (BChl a) y sus respectivas feofitinas se siguió el método descrito por Stal et al. (1984).

La determinación de proteínas se llevó a cabo usando el método de azul de Coomassie (Bradford 1976). Se usaron para su determinación los sedimentos remanentes de la extracción con metanol.

\section{Recuento de microorganismos viables}

El recuento de bacterias reductoras de sulfato (SRB) en los sedimentos se realizó en placas según el método descrito por Battersby (1988) utilizando el medio Iverson (Iverson 1966). Para la determinación cualitativa de la presencia/ausencia de SRB en los sedimentos se siguió a Holt \& Krieg (1994). 


\section{Análisis mineralógico por difracción de rayos $X$}

Se cortaron secciones horizontales de los testigos, se eliminó el agua contenida con la ayuda de papel de filtro para evitar la precipitación de $\mathrm{NaCl}$ en el proceso de secado, y luego se secaron en estufa. El proceso de preparación de las muestras se completó con la pulverización. El análisis mineralógico de muestras de tres horizontes del Sitio $\mathrm{D}$ se realizó por difracción de rayos $\mathrm{X}$ (DRX). Se utilizó un difractómetro Siemens modelo D5000 con monocromador secundario de grafito y detector de centelleo $\mathrm{NaI}$ (Tl) utilizando radiación de $\mathrm{CuKa}$ 1. Por la observación macroscópica y microscópica de las muestras, se asumió que el resto de los horizontes de cada sitio tenía una composición mineralógica similar.

\section{Clasificación de cianobacterias, diatomeas y bacterias anoxigénicas}

La clasificación de cianobacterias fue realizada utilizando el Manual de Bergey (Castenholz 2001) y Ripka et al. (1979). Se siguió a Round et al. (1990) para la asignación genérica de las diatomeas. Para la diferenciación de las bacterias fototróficas anoxigénicas se utilizaron las características señaladas por el Manual de Bergey (Holt et al. 1994).

\section{RESULTADOS}

Cambios visibles en el aspecto de los tapetes

En el presente estudio se observa que el nivel de agua que cubre los tapetes en los sitios muestrea- dos fluctúa considerablemente en las dos estaciones que se diferencian, invierno y verano. En el principio del verano (diciembre) no hay agua sobre los tapetes, pero después de precipitaciones producidas durante el fenómeno meteorológico conocido como invierno altiplánico (enero-marzo) u otros episodios aislados de precipitaciones, el nivel de agua observado sobre los tapetes alcanza un espesor máximo de hasta $5 \mathrm{~cm}$.

\section{Características fisicoquímicas}

Los valores de los parámetros fisicoquímicos recogidos en el campo y sobre las muestras de agua intersticial se resumen en la Tabla 1 . La salinidad del agua intersticial y la que cubre los tapetes es mayor en el comienzo del verano, alcanzando valores de hasta $33,4 \%$ (Tabla 1). No se observan cambios significativos de temperatura en invierno y verano. El pH de las salmueras es mayor en invierno que en verano y sus valores oscilan entre 7,0 y 8,5 .

Para una mejor caracterización de los sistemas en estudio, en la campaña de muestreo de diciembre de 1998 se procedió, también, a la determinación del contenido de sodio, potasio, calcio, magnesio, bicarbonato, cloruro, sulfato y silicato de las salmueras del Puquio 2, cuyos resultados se muestran en la Tabla 2. Además, la concentración promedio de litio en las salmueras es de $0,83 \mathrm{mM}$, la de boro $6.32 \mathrm{mM}$ y la de arsénico 0,095mM.

\section{Composición mineralógica de los sedimentos}

Los datos obtenidos del análisis de DRX muestran que los sedimentos en contacto con

TABLA 1

Parámetros fisicoquímicos medidos en el agua libre e intersticial

Physico-chemical parameters of free and interstitial waters

\begin{tabular}{|c|c|c|c|c|c|c|}
\hline Sitio de muestreo & Fecha & $\begin{array}{l}\text { Espesor de la columna } \\
\text { de agua sobre el tapete } \\
(\mathrm{cm})\end{array}$ & $\begin{array}{c}\text { Temperatura } \\
\left({ }^{\circ} \mathrm{C}\right)\end{array}$ & $\begin{array}{l}\text { Salinidad } \\
(\%)\end{array}$ & $\begin{array}{c}\text { Conductividad } \\
(\mathrm{mS})\end{array}$ & $\mathrm{pH}$ \\
\hline \multirow[t]{2}{*}{ Sitio A } & Jul 1999* & 0,0 & ND & 12,60 & 184,0 & 7,9 \\
\hline & Dic 1999* & 0,0 & ND & 33,40 & 511,0 & 7,8 \\
\hline \multirow[t]{3}{*}{ Sitio B } & Dic 1998 & ND & 23,0 & ND & 138,2 & 8,0 \\
\hline & Jul 1999 & 3,5 & 22,0 & 3,29 & 40,4 & 8,5 \\
\hline & Dic 1999* & ND & ND & 21,80 & 188,7 & 7,0 \\
\hline \multirow[t]{3}{*}{ Sitio D } & Dic 1998 & ND & 21,0 & ND & 185,7 & 7,8 \\
\hline & Jul 1999 & 3,5 & 23,0 & 5,11 & 71,6 & 8,5 \\
\hline & Dic 1999* & 0,0 & ND & 20,90 & 176,4 & 7,5 \\
\hline Sitio E & Jul 1999 & 5,0 & 16,4 & 0,10 & 2,0 & 8,1 \\
\hline
\end{tabular}

(*) Agua intersticial

(ND) No determinado 
TABLA 2

Análisis químicos de las salmueras en diferentes sitios del Puquio 2, realizados en diciembre de 1998. La localización de los sitios muestreados en esa ocasión se indican en la Fig. 2

Analysis of brines at different stations in Puquio 2 carried out in December 1998. Location of sampling sites is shown in Fig. 2

\begin{tabular}{cccccccrrrr}
\hline Muestra & $\mathrm{pH}$ & $\begin{array}{c}\text { Temperatura } \\
\left({ }^{\circ} \mathrm{C}\right)\end{array}$ & $\begin{array}{c}\mathrm{Na}^{+} \\
(\mathrm{mM})\end{array}$ & $\begin{array}{c}\mathrm{K}^{+} \\
(\mathrm{mM})\end{array}$ & $\begin{array}{c}\mathrm{Ca}^{2+} \\
(\mathrm{mM})\end{array}$ & $\begin{array}{c}\mathrm{Mg}^{2+} \\
(\mathrm{mM})\end{array}$ & $\begin{array}{r}\mathrm{HCO}_{3}{ }^{-} \\
(\mathrm{mM})\end{array}$ & $\begin{array}{c}\mathrm{Cl}^{-} \\
(\mathrm{mM})\end{array}$ & $\begin{array}{r}\mathrm{SO}_{4}{ }^{2-} \\
(\mathrm{mM})\end{array}$ & $\begin{array}{c}\mathrm{SiO}_{2} \\
(\mathrm{mM})\end{array}$ \\
\hline 1 & 7,5 & 30 & 1516,3 & 29,9 & 25,0 & 79,4 & 3,2 & 1198,8 & 261,7 \\
2 & 7,8 & 21 & 3109,6 & 56,3 & 26,2 & 125,5 & 4,4 & 2637,3 & 496,0 & 1,3 \\
3 & 7,8 & 21 & 3254,1 & 57,0 & 18,5 & 112,7 & 3,6 & 2648,6 & 506,7 & 1,0 \\
4 & 7,6 & 24 & 3261,4 & 54,0 & 27,9 & 122,6 & 3,6 & 2634,5 & 471,7 & 0,9 \\
5 & 7,9 & 20 & 431,5 & 9,2 & 20,5 & 21,8 & 3,2 & 420,3 & 88,7 & 1,7 \\
6 & 8,1 & 24 & 629,0 & 13,3 & 27,2 & 40,3 & 3,6 & 524,6 & 116,6 & 1,7 \\
7 & 8,2 & 21 & 472,4 & 9,5 & 25,5 & 25,1 & 3,6 & 380,8 & 89,5 & 1,7 \\
8 & 8,0 & 23 & 926,5 & 37,6 & 21,0 & 79,4 & 4,0 & 1534,4 & 294,1 & 1,4 \\
9 & 7,8 & 22 & 3131,0 & 56,3 & 22,0 & 85,6 & 4,8 & 2674,0 & 502,9 & 0,9 \\
\hline
\end{tabular}

las salmueras están compuestos principalmente por minerales salinos como yeso con trazas de thenardita y halita, además de hornblenda y montmorillonita.

\section{Descripción macroscópica}

En esta sección se describe el grosor y la distribución de las capas en los tapetes microbianos estudiados (Tabla 3).

El espesor de los tapetes descritos oscila entre 8 y $30 \mathrm{~mm}$, considerando las capas pigmentadas. Se observan diferencias en la distribución de las capas en los tapetes de los Sitios A, B, C y D. En el Sitio E no se observa desarrollo de tapete microbiano. En el Sitio A se encuentran dos capas coloreadas, una capa naranja y otra verde, que conforman un tapete de $5 \mathrm{~mm}$ de espesor. Algunas manchas color púrpura aparecen debajo de la capa verde en el trabajo realizado en invierno, pero no conforman una capa continua. El espesor del tapete del Sitio B mide entre 28 y $30 \mathrm{~mm}$ y está compuesto, de arriba hacia abajo, por una capa verde, una púrpura, una blanquecina y, finalmente, una capa color verde claro (Fig. 3, I). El tapete del sitio $C$ presenta una sola capa de color verde de $5 \mathrm{~mm}$ de espesor (Fig. 3, II). El tapete del Sitio D tiene un espesor entre 8 a 19 $\mathrm{mm}$. Se encuentran en este último, desde la parte superior, una laminación naranja, luego la capa verde y finalmente la capa de color púrpura. Todos los tapetes están cubiertos en su superficie por una costra salina de color blanco con un espesor variable entre 5 y 10 mm. En los Sitios B y D pueden verse cristales de yeso en esta costra, mientras que en el Sitio A se encuentran también cristales de halita.
Debajo del tapete laminado los sedimentos, en general, son blanquecinos y están compuestos por yeso. Sin embargo, se observan cambios estacionales en los distintos sitios de muestra. Por ejemplo, en el Sitio A la coloración debajo del tapete, en invierno y verano, es parda debido a un mayor contenido de arcilla. A su vez, el mismo horizonte estratigráfico en el Sitio B, en verano de 1998 , era de color negro, aproximadamente a $40 \mathrm{~mm}$ de profundidad.

\section{Descripción microscópica}

La observación microscópica de la morfología de las células que se encuentran en cada una de las capas de los Sitios A, B, C, D y E, acompañada de los datos obtenidos del análisis de los pigmentos correspondientes permite caracterizar los microorganismos que las componen (Tabla 3).

En todas las capas de los Sitios B, C y D se encuentran frústulas de diferentes especies de diatomeas. Las diatomeas son los microorganismos más abundantes en las laminaciones naranja, encontrándose en menor proporción en las laminaciones verdes (Fig. 4, I y II).

Las cianobacterias filamentosas, Microcoleus sp. y Oscillatoria sp. (Fig. 4, IV, V y VII) son más abundantes en las laminaciones verdes, mientras que las cianobacterias cocoides son más abundantes en la capa naranja. Las diferencias en la composición de la población bacteriana en el Sitio A respecto de los Sitios B y D, está marcada por el predominio de cianobacterias cocoides (Fig. 4, VI y VIII) en la laminación verde y la ausencia de diatomeas en la laminación naranja. En las laminaciones púrpuras los microorganismos predominantes corresponden a bacilos de $6 \mu \mathrm{m}$ de largo y $2 \mu \mathrm{m}$ de diá- 
TABLA 3

Descripción macro y microscópica de las capas que conforman los tapetes microbianos

Macro and microscopic description of layers making up microbial mats

\begin{tabular}{|c|c|c|c|}
\hline \multicolumn{4}{|c|}{ Puquio 1} \\
\hline Descripción & Grosor $(\mathrm{mm})$ & Microorganismos fototróficos más abundantes & SRB \\
\hline \multicolumn{4}{|l|}{ Sitio A } \\
\hline Costra salina & 10 & $\mathrm{~b}$ & - \\
\hline Capa naranja & $3-5$ & $C$ y $S$ & + \\
\hline Capa verde & $2-3$ & $S, C, G, G c, M$, у $O$ & + \\
\hline Capa parda & $20-50$ & Bac, cc y $S^{c}$ & + \\
\hline \multicolumn{4}{|c|}{ Puquio 2} \\
\hline \multicolumn{4}{|l|}{ Sitio B } \\
\hline Costra salina & $5-7$ & $S$ & + \\
\hline Capa verde & 5 & $M, O, S, A, N, N v, E, D$ y bac & + \\
\hline Capa púrpura & $8-10$ & bac, cc, $M, O, A n, S$, escasas diatomeas & + \\
\hline Capa blanca & 5 & $\mathrm{~b}$ & + \\
\hline Capa verde claro & 10 & $D m^{d}, D m, S, M$, bac, cc & + \\
\hline \multicolumn{4}{|l|}{ Sitio C } \\
\hline Costra salina & 5 & $\mathrm{~b}$ & ND \\
\hline Capa crema & 18 & $\mathrm{~b}$ & ND \\
\hline Capa verde & 5 & $O, D m, A, N, D, E, N v$ & ND \\
\hline \multicolumn{4}{|l|}{ Sitio D } \\
\hline Costra salina & 5 & $D m, S, O, M$, diatomeas & + \\
\hline Capa naranja & $3-6$ & $A, N, D, E$ y $N v ; S, D m, M$, bac & + \\
\hline Capa verde & $3-9$ & $M, O, S, P, D m, A n$, bac, diatomeas como en capa naranja & + \\
\hline Capa púrpura & $2-3$ & bac, cc, $M, O, A n, S$, diatomeas & + \\
\hline \multicolumn{4}{|c|}{ Puquio 3} \\
\hline \multicolumn{4}{|l|}{ Sitio E } \\
\hline Sedimentos superficiales & 10 & $D m, G t, A n$, diatomeas. & ND \\
\hline
\end{tabular}

(a) + presencia, - ausencia; (b) no se observan; (c) solo se observaron en diciembre de 1999; (d) julio 1999; (ND) no determinado; (C) Cianothece sp.; (S) Synechococcus sp.; (G) Gloeobacter sp.; (Gc) Gloeocapsa sp.; (bac) bacilos de 6 x 2 mm; (cc) células cocoides de 1,5 a 2 mm; (M) Microcoleus sp.; (O) Oscillatoria sp.; (A) Amphora sp.; (N) Nitzschia sp.; $(N v)$ Navicula sp.; (E) Entomoneis sp.; (D) Diatoma sp.; (An) Anabaena sp.; (Dm) Dermocarpa sp.; (P) Pleurocapsa sp.; (Gt) Gloeothece sp.

metro, autofluorescentes, móviles, no presentan vacuolas de gas y tienen forma de bacilos redondeados semejantes a células del género Chromatium, aunque no se observan gránulos de azufre en su interior. Sin embargo, sí se distinguen gránulos de azufre en el interior de este tipo de células, de $10 \mu \mathrm{m}$ de largo y de 3-5 $\mu \mathrm{m}$ de diámetro, en tapetes en los que la capa negra está presente (Sitio B, diciembre de 1998 y Sitio 7 en marzo de 2000). Se observan, también, en las capas púrpuras abundantes microorganismos cocoides de 1,5 a $2 \mu \mathrm{m}$ de diámetro, inmóviles, frecuentemente en agregados de dos células, semejantes a bacterias del género Thiocapsa (Fig. 4, III).

Además de los señalados, se observan en todas las laminaciones de los tapetes abundan- tes microorganismos no fototróficos, $\operatorname{cocos} \mathrm{y}$ bacilos no identificados. Entre las poblaciones heterótrofas se han estudiado especialmente las SRB por su importancia biogeoquímica en estos ecosistemas. El desarrollo de bacterias reductoras de sulfato es positivo en todas las capas analizadas menos en la capa superior del Sitio A (Tabla 3). La observación microscópica de los cultivos enriquecidos en las experiencias para la determinación cualitativa de la presencia/ausencia de SRB, revela la existencia de tres morfologías diferentes, vibriones, espirilos y bacilos. El promedio del recuento de SRB es de $2.2 \times 10^{4} \mathrm{CFU} \mathrm{ml}{ }^{-1}$ de sedimento en las diferentes capas del Sitio D en invierno, seleccionado por ser el sitio con el tapete más estructurado. 
B

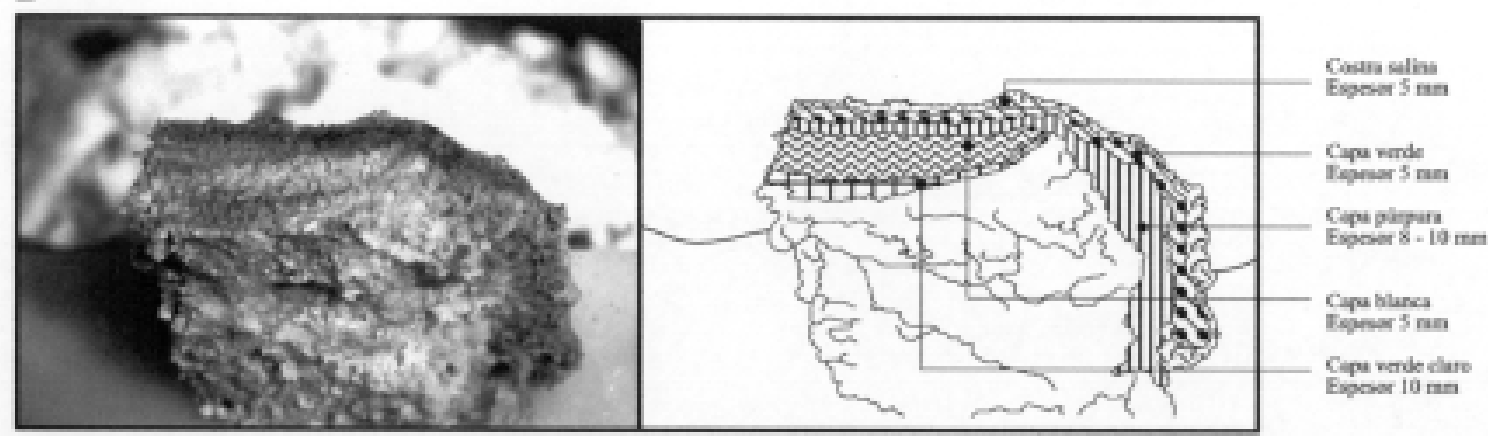

C

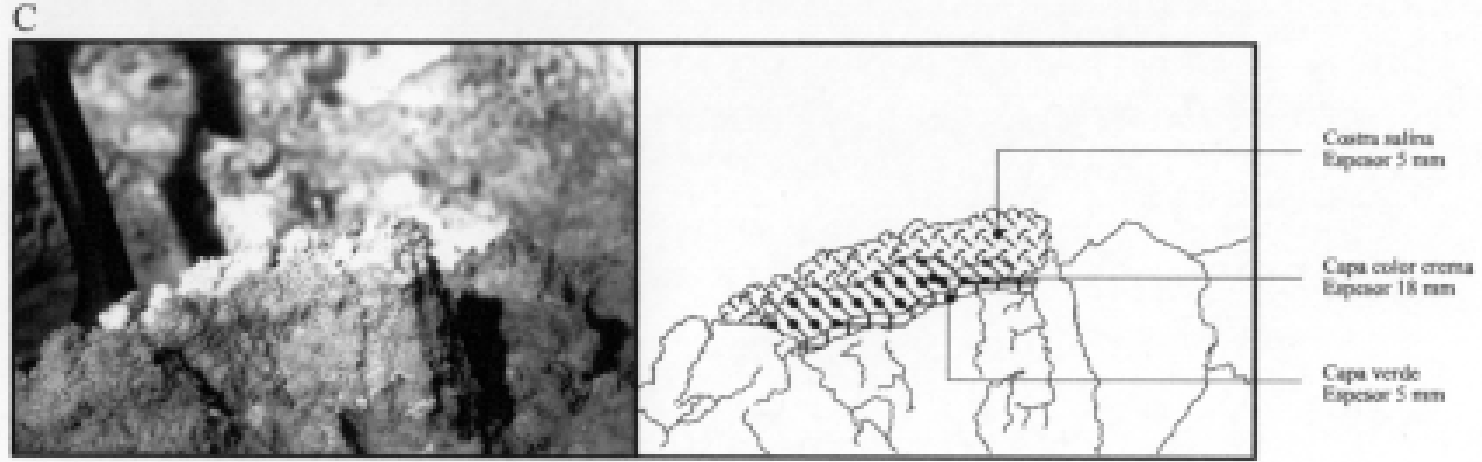

Fig. 3: Secciones verticales de los tapetes microbianos de los Sitios B y C.

Vertical sections through microbial mats at Stations B and C.

\section{Análisis de pigmentos y proteínas}

En la Fig. 5 se muestran los perfiles de la distribución de pigmentos y proteínas de los sistemas analizados. Los espectros de absorción revelan que la $\mathrm{Chl}$ a es el pigmento fotosintético más abundante en la capa verde en los tres sitios analizados. La BChl a, por otra parte, es el pigmento más abundante en la capa de color púrpura en las muestras tomadas en invierno en el Sitio B. La relación entre Chl a y BChl a es menor en la capa púrpura que en las otras capas en las muestras del Sitio B tomadas en verano y en las muestras del Sitio D. Los contenidos de Chl a y BChl a aumentan en invierno en todos los sitios analizados, indicando un mayor desarrollo de los tapetes en la temporada con más agua superficial.

El perfil de la concentración de proteínas manifiesta un aumento en los milímetros superficiales de los tapetes de los Sitios A y D muestreados en invierno (Fig. 5A y C), alcanzando un máximo entre los 6 y $20 \mathrm{~mm}$ y una disminución a mayores profundidades. En el sitio B, en cambio, se observa un aumento del nivel de proteínas en la capa blanca ubicada debajo de la laminación púrpura del Sitio B muestreado en julio (Fig. 5B). En los tapetes muestreados en verano, la concentración de proteínas es en promedio un orden de magnitud menor que en invierno y no se observan diferencias en el espesor del tapete.

La Fig. 6 resume el resultado de la integración de los valores de Chl a y Bchl a en todo el grosor de la zona fototrófica de cada uno de los sitios estudiados (A, B, C, D y E).

En el Sector $\mathrm{C}$ ubicado en el margen sur del Puquio 2, el contenido de Chl a en la laminación verde a una profundidad de $23 \mathrm{~mm}$, debajo de la costra salina, es de $1,21 \mathrm{mg} \mathrm{g}^{-1}$ y la concentración de proteínas de $0,026 \mathrm{mg} \mathrm{g}^{-1}$. En el sector E, localizado en los márgenes del Puquio 3 , el contenido de $\mathrm{Chl}$ a en el sedimento negro, es de $5,15 \mathrm{mg} \mathrm{g}^{-1}$ y la concentración de proteínas de $0,26 \mathrm{mg} \mathrm{g}^{-1}$.

\section{DISCUSIÓN}

Este trabajo constituye la primera descripción de tapetes microbianos en Chile. Además de las comunidades encontradas en el Salar de Llamará, objeto del presente estudio, los autores han observado la presencia de este tipo de ecosistemas en los salares de Atacama, Ascotán y Carcote, todos localizados en el norte de Chile. Aunque 
I

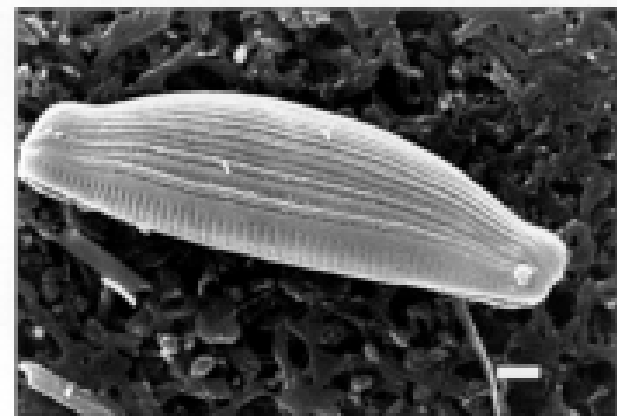

III

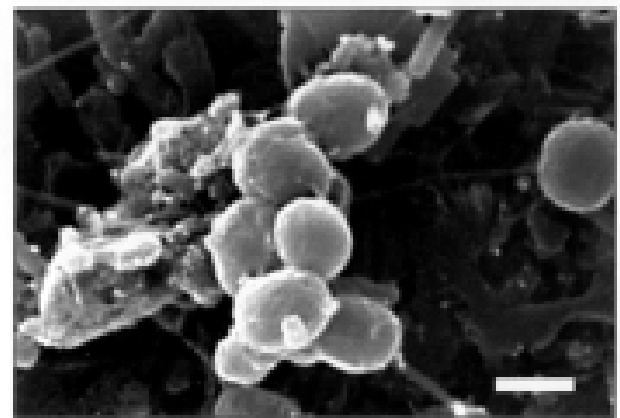

$\mathbf{V}$

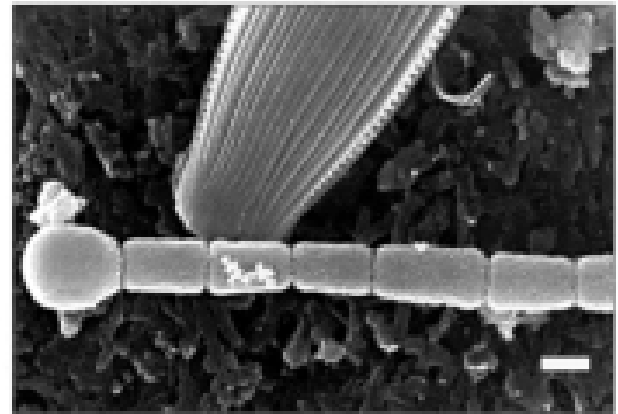

VII

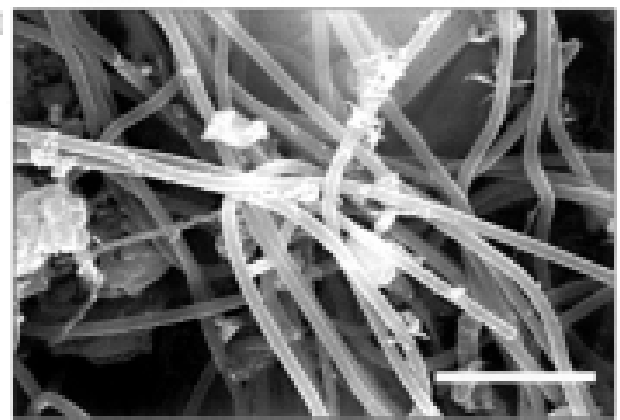

II

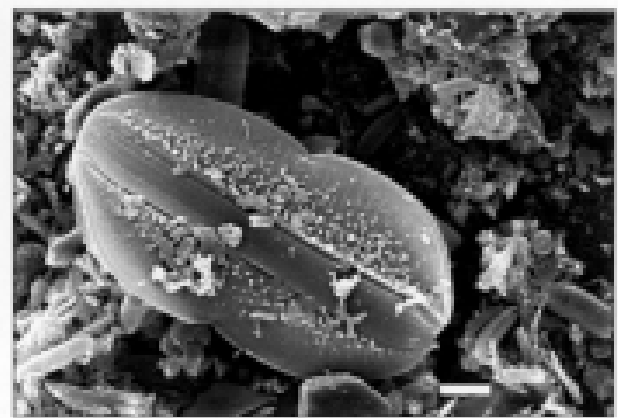

IV

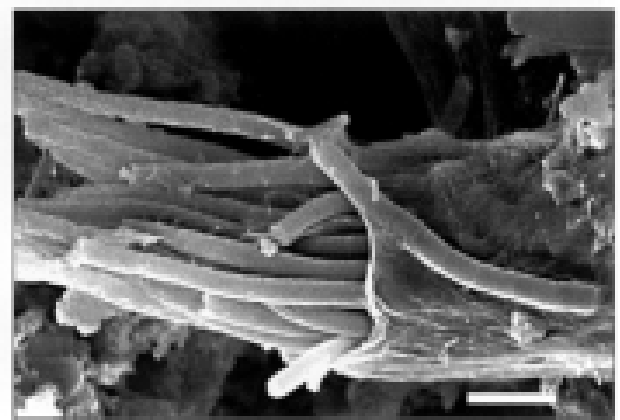

VI

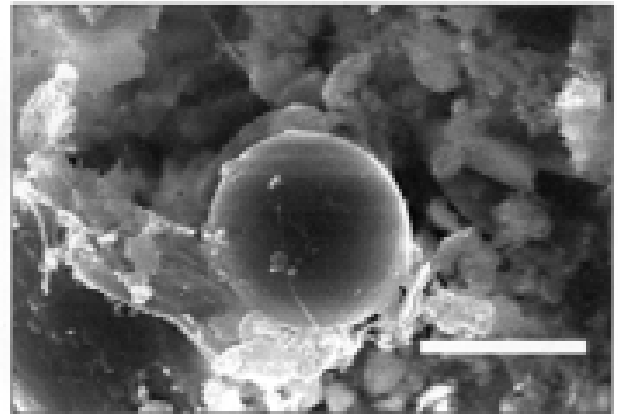

VIII

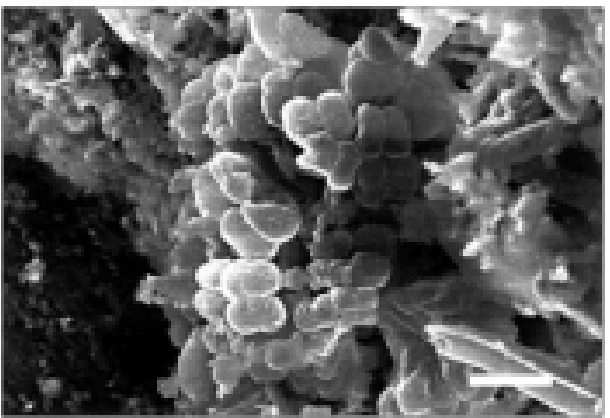

Fig. 4: Microfotografías obtenidas por microscopía electrónica de barrido que muestran las diatomeas y bacterias fototróficas que constituyen los tapetes microbianos de los Sitios A, B y D: I y II Amphora sp. y Entomoneis sp. (Sitio B); III bacterias del azufre (Sitio B); IV Microcoleus sp. (Sitio D); V Anabaena sp. (Sitio D); VI Cianobacteria unicelular (Sitio D); VII Oscillatoria sp. (Sitio A); VIII grupo de cianobacterias unicelulares (Sitio A); las barras de escala son equivalentes a $1 \mathrm{~mm}$ para las imágenes I, III y V y a $10 \mathrm{~mm}$ para las restantes.

Scanning electron microphotographs showing diatoms and phototrophic bacteria which constitute microbial mats at Stations A, B and D: I and II Amphora sp. and Entomoneis sp. (Station B); III sulphur bacteria (Station B); IV Microcoleus sp. (Station D); V Anabaena sp. (Station D); VI unicellular Cyanobacteria (Station D); VII Oscillatoria sp. (Station A); VIII groupings of unicellular Cyanobacteria (Station A); scale bar is equivalent to $1 \mathrm{~mm}$ for images I, III and V and $10 \mathrm{~mm}$ for images II, IV, VI, VII and VIII. 

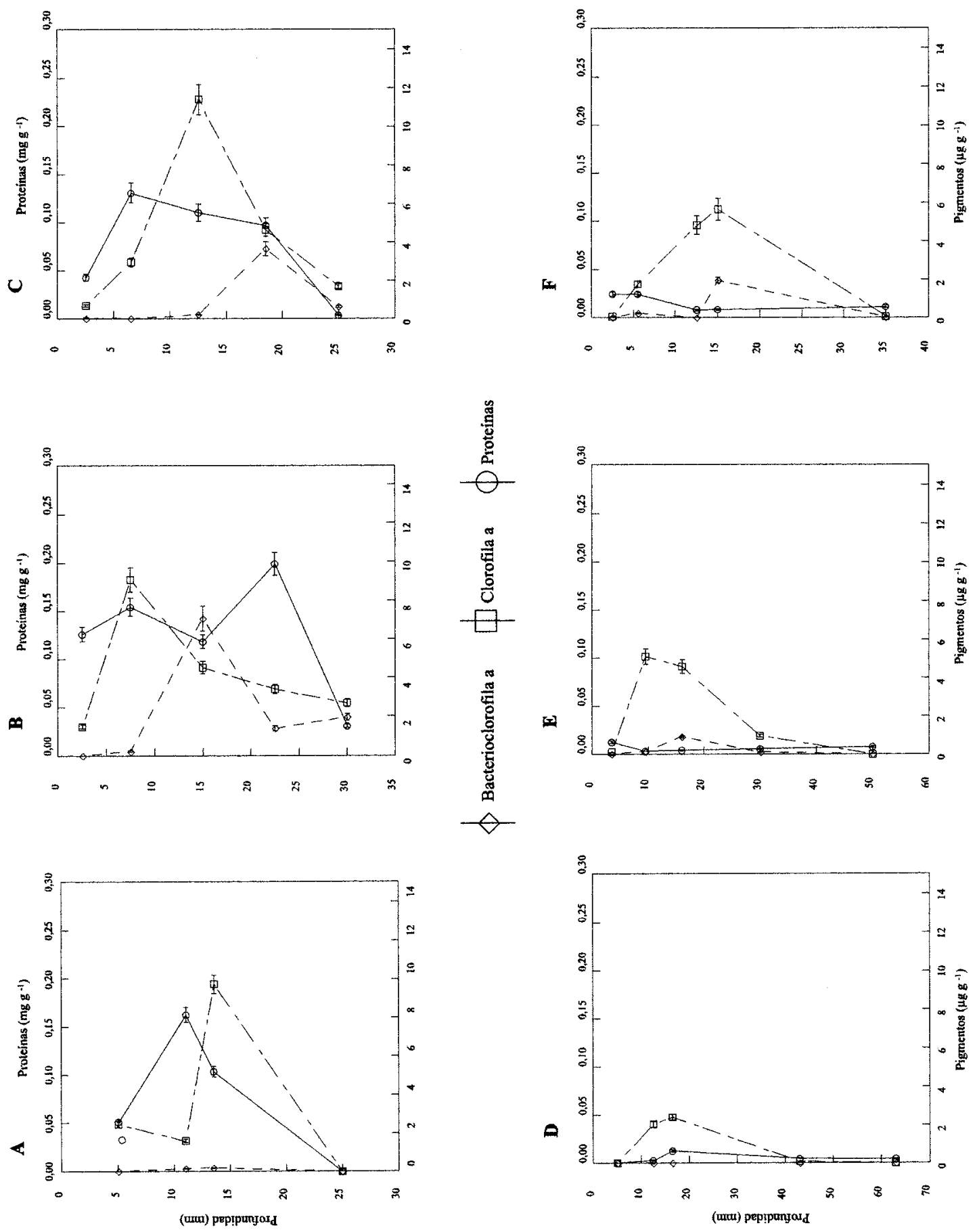

Fig. 5: Distribución vertical de las concentraciones de pigmentos y proteínas de los tapetes estudiados en invierno, julio de 1999 (A-C), y verano, diciembre de 1999 (S-F). Se muestran los perfiles del Sitio A (A y D), Sitio B (B y E) y Sitio D (C y F). Las barras de error representan el error estándar de las medias de dos determinaciones. En algunos casos las barras de error están incluidas en el dibujo del símbolo correspondiente.

Vertical distribution of pigment and protein concentrations in the studied mats in winter, July 1999 (A-C), and summer, December 1999 (D-F). Profiles from Station A (A and D), Station B (B and E) and Station D (C and F) are shown. Error bars represent standard errors of the means of two determinations. Error bars are included in the symbols in some plots. 


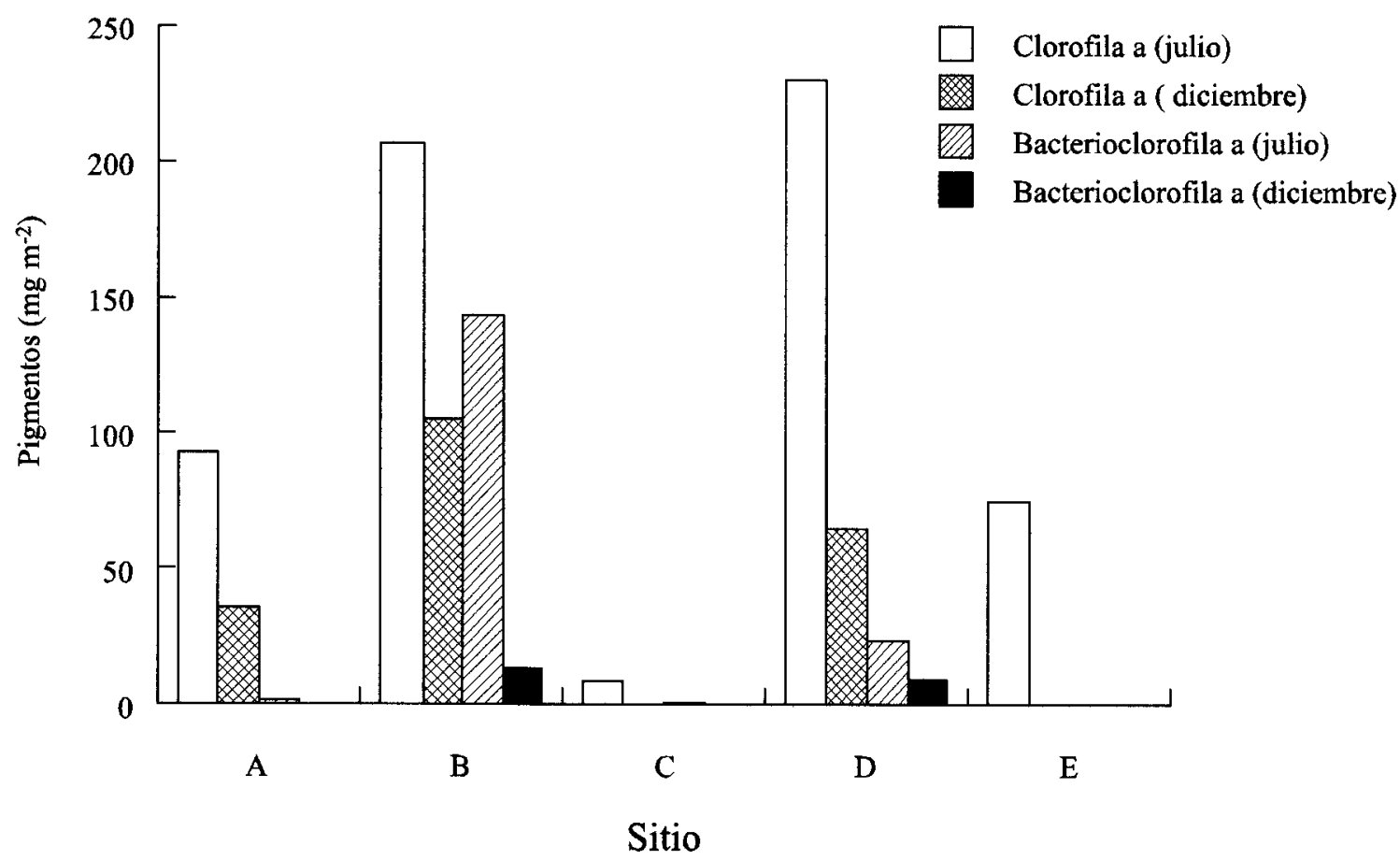

Fig. 6: Valores integrados de $\mathrm{Chl}$ a y $\mathrm{BChl}$ a por unidad de área en cada uno de los sitios estudiados (A, B, C, D y E).

Integrated values for $\mathrm{Chl}$ a and $\mathrm{BChl}$ a per unit area in the studied stations ( $\mathrm{A}, \mathrm{B}, \mathrm{C}, \mathrm{D}$ and $\mathrm{E})$.

Karsten (1996) ya mencionó la existencia de comunidades multilaminadas en la Estación Marina Intermareal de Dichato, localizada en la zona sur del país y realizó un estudio a partir de cianobacterias aisladas de este, hasta este momento no se tenía información sobre la ubicación de dichos tapetes ni sobre los parámetros bióticos y abióticos que condicionan su crecimiento.

Los resultados de los análisis fisicoquímicos revelan que el rango de $\mathrm{pH}$ de las salmueras y la disminución del mismo observada en verano concuerda con los resultados publicados por Garcés et al. (1998) que clasifica las salmueras como neutras ya que su pH oscila entre 7 y 8,3 y muestran una tendencia descendente del $\mathrm{pH}$ a lo largo del proceso de evaporación. Se observan, además, diferencias en la concentración de cloruro entre los puntos muestreados de hasta $2.290 \mathrm{mM}$ (Tabla 2). Esta heterogeneidad ha sido puesta de manifiesto, también, en publicaciones anteriores (López et al. 1999) y es posiblemente una de las causas de las diferencias locales en los tapetes estudiados.

La distribución de las capas pigmentadas en los tapetes del Salar de Llamará es similar a las descritas de otros tapetes en hábitats hipersalinos (Stolz \& Margulis 1984, Giani et al. 1989).
Los tapetes observados en el Salar son heterogéneos. Por una parte falta la laminación naranja en el tapete del Sitio B, aunque se evidencia la presencia de diatomeas normalmente asociadas a laminaciones de este color. La ausencia de la laminación púrpura en el Sitio A puede deberse a las condiciones de oxigenación del sector, dado que este permanece sin agua en su superficie durante todo el tiempo observado. La presencia de una laminación con las características propias de los fotótrofos oxigénicos debajo de una capa de fotótrofos anoxigénicos en el tapete del Sitio B puede corresponder a un tapete antiguo, fotosintéticamente no activo, de acuerdo al nivel de pigmentos, sepultado por nuevos sedimentos. En algunos de los puntos de muestreo se observa escaso desarrollo tanto de la zona fototrófica como del horizonte negro, pudiendo incluso faltar este último. Sin embargo en los tapetes consolidados la capa fototrófica anoxigénica se encuentra bien desarrollada debajo de las fototróficas oxigénicas. Las observaciones realizadas en las distintas épocas del año evidencian un mayor desarrollo de los tapetes de todos los sitios analizados en el invierno, cuando el nivel de agua es mayor, evidenciado por el aumento en la concentración y 
el contenido de pigmentos y en los niveles de proteínas. Otro de los cambios estacionales observados es la presencia (diciembre de 1998) o ausencia (julio y diciembre de 1999) del horizonte negro debajo de las laminaciones coloreadas dependiendo de las condiciones que permiten el desarrollo de ambientes microaerofílicos, y la estructuración de una comunidad fotosintética productora de materia orgánica. El Sitio B, que es el que presenta mayor desarrollo del tapete microbiano, es también el que permanece por más tiempo inundado durante el año, impidiendo la difusión del oxígeno, lo que favorece el desarrollo de la comunidad anoxigénica. La reoxidación del sulfuro de hidrógeno en las zonas oxigenadas podría ser responsable de la ausencia de la coloración negra en los sedimentos bajo los tapetes (Habicht \& Canfield 1996). El sulfuro generado por la actividad de las SRB podría ser reoxidado debajo de la costra probablemente por oxidación química con el oxígeno que difunde desde la superficie más el producido en la capa verde, por el metabolismo quimiotrófico de bacterias oxidadoras del azufre que se ha encontrado que son abundantes y por la fotosíntesis anoxigénica de las bacterias púrpuras, en la capa púrpura (Caumette et al. 1994).

Las observaciones con microscopio de contraste de fase, de epifluorescencia y electrónico de barrido se correlacionan bien con el análisis de los pigmentos. En las capas verde y naranja de los sitios A, B y D, donde los microorganismos predominantes son cianobacterias y diatomeas, la Chl a constituye entre el 91 y $99 \%$ del total de los pigmentos clorofílicos valorados $(\mathrm{Chl} \mathrm{a}+\mathrm{BChl}$ a). Por otra parte la BChl a presenta un máximo en las capas púrpuras que se encuentran en los Sitios B y D, constituyendo el 61 y $44 \%$, respectivamente, del total de clorofila. La observación microscópica revela la presencia, en estas laminaciones, de bacterias púrpuras del azufre.

$\mathrm{Si}$ se consideran los valores integrados en todo el espesor del tapete, el Sitio B presenta el mayor contenido de los principales pigmentos fotosintéticos analizados $(=\mathrm{Chl} \mathrm{a}+\mathrm{Bchl} \mathrm{a})$, en el muestreo de invierno $\left(350,8 \mathrm{mg} \mathrm{m}^{-2}\right)$. El 40,9\% de este total corresponde a BChl a. Esto sugiere una mayor contribución de las bacterias fototróficas anoxigénicas en la producción primaria del tapete.

El descenso de la concentración de proteínas con la profundidad observado en los tapetes muestreados en invierno se asemeja a lo informado por Martínez-Alonso 1997, atribuido por la autora a los procesos de mineralización. El aumento de la concentración de proteínas en la capa blanquecina del Sitio B respecto de las capas coloreadas superiores, podría indicar la presencia de bacterias quimiolitotróficas no coloreadas. Estas se localizan con frecuencia en una capa blanca ubicada entre la capa de bacterias fotosintéticas oxigénicas y la de bacterias anoxigénicas en la estrecha zona donde el oxígeno y el sulfuro coexisten. Se ha encontrado que estas bacterias son los constituyentes predominantes de los tapetes cercanos a las vertientes termales en el fondo del mar (Belkin \& Jannash 1985).

El grosor de los tapetes analizados en el presente trabajo es de 8 a $30 \mathrm{~mm}$ mientras que otros descritos previamente por otros autores (Stal et al. 1984, Mir et al. 1991, Esteve et al. 1992, Caumette et al. 1994, Teske et al. 1998) tienen entre 3,5 y $13 \mathrm{~mm}$ de espesor. Esto se debe probablemente a las diferencias en la granulometría y composición de los sedimentos. La arena fina se caracteriza por aumentar el ascenso del agua freática por capilaridad (Hofmann 1942) y favorecer la penetración de la luz roja e infrarroja (Hofmann 1949, Kühl et al. 1994), mientras que la luz es rápidamente extinguida en arcillas limosas (Guerrero et al. 1994). Probablemente la penetración de la radiación infrarroja se ve también favorecida por los cristales de yeso y la halita. Se ha informado, además, que en horizontes donde las mediciones con microelectrodos han demostrado condiciones con grandes fluctuaciones, los microorganismos no se concentran en finas bandas sino en capas de varios milímetros de espesor (Van den Ende et al. 1996). La atenuación de la luz visible, según determinaciones realizadas con microsondas de fibra óptica en tapetes bacterianos artificiales, es 100 veces mayor que la de la luz cercana al infrarrojo. Este hecho favorece la proliferación de bacterias fotosintéticas anoxigénicas en zonas más profundas del tapete bacteriano (Kühl \& Fenchel 2000).

El predominio de las cianobacterias filamentosas de los géneros Microcoleus y Oscillatoria en las laminaciones de color verde concuerda con lo informado acerca de los dominios de extensión en función de la salinidad de diferentes microorganismos fototróficos oxigénicos que constituyen los tapetes microbianos de ambientes salinos e hipersalinos (Thomas 1984, de Wit \& Caumette 1994). El predominio de cianobacterias cocoides en la laminación verde y la ausencia de diatomeas en la laminación naranja observados en el tapete de sitio A, por otra parte, puede deberse a la mayor salinidad de las salmueras como consecuencia de la baja recarga de este sector del Salar. De acuerdo a las investigaciones realizadas previamente 
(Thomas 1984, de Wit \& Caumette 1994, Martínez-Alonso 1997), las cianobacterias cocoides son los principales componentes de tapetes en ambientes con salinidad elevada mientras que las diatomeas se encuentran en tapetes microbianos en ambientes donde la salinidad no sobrepasa el $10 \%$.

La presencia de gránulos de azufre en los bacilos redondeados semejantes a células del género Chromatium se observa solo en las laminaciones púrpura de los tapetes en los que la presencia de sulfuro, evidente por la presencia del horizonte negro, permite la actividad oxidante (Holt et al. 1994b) y la acumulación de azufre.

Los géneros bacterianos Chromatium y Thiocapsa encontrados en estos sistemas son los más comúnmente aislados de ambientes marinos e hipersalinos (Ollivier et al. 1994). Nuevas especies aisladas del género Thiocapsa crecen en salinidades entre 4 y $20 \%$ de $\mathrm{NaCl}$, con un crecimiento óptimo entre 6 y $10 \%$ de $\mathrm{NaCl}$ (Ollivier et al. 1994). Estudios realizados tanto en ambientes naturales como en condiciones controladas de laboratorio han puesto de manifiesto la versatilidad metabólica de estas bacterias fototróficas (Herbert 1985, De Wit \& Van Gemerden 1990, Herbert \& Welsh 1994), pudiendo incluso crecer en sedimentos expuestos al aire por su tolerancia al oxígeno. Las notables fluctuaciones de los parámetros fisicoquímicos a las que están sometidas este tipo de comunidades multilaminadas favorecen la colonización por microorganismos con elevada capacidad de adaptación.

Los valores de los recuentos de SRB realizados en las diferentes capas del Sitio D en invierno son similares a los encontrados en invierno en Saline-de-Giraud (Caumette et al. 1994). Sin embargo, en Solar Lake los niveles de SRB cultivables, determinados por el método del Número más Probable, son tres órdenes de magnitud superiores en las capas superficiales oxigenadas de los tapetes microbianos (Teske et al. 1998). Se ha detectado actividad bacteriana reductora de sulfato bajo condiciones aeróbicas en tapetes microbianos (Fründ \& Cohen 1992). Probablemente los recuentos más bajos de la población de SRB se deben a una menor disponibilidad de materia orgánica por este grupo de microorganismos. Estudios anteriores revelan la dependencia de las SRB de la materia orgánica (Caumette et al. 1994).

Las concentraciones de pigmentos y proteínas de los tapetes microbianos estudiados aquí son bajas (Fig. 5) comparadas con los datos de tapetes bacterianos de ambientes marinos (Mar-
tínez-Alonso 1997). Los mayores contenidos de Chl a se detectan en los sitios B $\left(9,1 \mathrm{mg} \mathrm{g}^{-1}\right) \mathrm{y}$ D $\left(11,4 \mathrm{mg} \mathrm{g}^{-1}\right)$ en invierno. Es en estos sitios donde se observan también las máximas concentraciones de Bchl a $\left(7,1\right.$ y $3,6 \mathrm{mg} \mathrm{g}^{-1}$, respectivamente) en las laminaciones púrpuras. Estas concentraciones de pigmentos son dos órdenes de magnitud menores que los informados por Martínez-Alonso 1997. Si comparamos los valores integrados de $\mathrm{Chl}$ a y $\mathrm{BChl}$ a en toda la zona pigmentada (Fig. 6), los contenidos en el Salar de Llamará son diez veces menores que en los tapetes microbianos de la Península de los Alfaques (España) (Martínez-Alonso 1997) y los tapetes microbianos de Guerrero Negro, México (Palmisano et al. 1989).

Los tapetes estudiados se caracterizan por ser uno de los de mayor grosor descritos hasta el momento y por la presencia de microorganismos que predominan en ambientes de mayor salinidad. Las diferencias en las concentraciones de pigmentos y proteínas comparado con tapetes microbianos de ambientes marinos se deben probablemente a los parámetros fisicoquímicos a los que están sometidos los tapetes que aquí se describen, tales como la elevada salinidad.

Actualmente se desarrollan investigaciones utilizando métodos de biología molecular para el estudio de esta microbiota y su comparación con las encontradas en otras cuencas evaporíticas del Norte de Chile. Esto permitirá establecer asociaciones entre la biodiversidad en cada comunidad microbiana multilaminada y los parámetros fisicoquímicos tales como la temperatura, la composición de las salmueras y la acción antropogénica.

\section{AGRADECIMIENTOS}

Este trabajo fue financiado en parte por los proyectos FONDEF D97F1078 y FONDECYT 1970030 del Gobierno de Chile y en parte por el proyecto DGICT 1030133 de la Universidad Católica del Norte. Se agradece la colaboración del Laboratorio de Estado Sólido del Departamento de Química de la Universidad Católica del Norte, mediante el Proyecto FONDECYT 1990364, donde se realizaron los espectros de absorción. Agradecemos también las sugerencias y lectura crítica del manuscrito por parte de Juan José Pueyo, Facultad de Geología, Universidad de Barcelona y Carles Pedrós-Alió, Departamento de Biología Marina y Oceanografía del Instituto de Ciencias del Mar, del Consejo Superior de Investigación y Ciencia de España. 


\section{LITERATURA CITADA}

ALPERS CN \& DO WHITTEMORE (1990) Hydrogeochemistry and stable isotopes of ground and surface waters from two adjacent closed basins, Atacama Desert, northern Chile. Applied Geochemistry 5: 719-734.

BATTERSBY NS (1991) Sulphate reducing bacteria. En: Austin B (ed) Methods in aquatic bacteriology: 269299. John Wiley \& Sons Ltd., New Delhi, India.

BAULD J (1984) Microbial mats in marginal marine environments: Shark bay, Western Australia, and Spencer Gulf, South Australia. En: Cohen Y, RW Castenholz \& HO Halvorson (eds) Microbial mats stromatolites: 39-58. Alan R. Liss, New York, New York, USA.

BELKIN S \& HW JANNASH (1985) Biological and abiological sulfur reduction at high temperatures. Applied and Environmental Microbiology 49: 1057-1061.

BRADFORD MM (1976) A rapid and sensitive method for the quantification of micrograms quantities of protein utilizing the principle of protein-dye binding. Analytical Biochemistry 72: 248-254.

BROCK TD (1978) The habitats: thermophilic microorganisms and life at high temperatures. Springer-Verlag, New York, New York, USA. 465 pp.

CASTENHOLZ RW (1984) Composition of hot spring microbial mats: a summary. En: Cohen Y, RW Castenholz \& HO Halvorson (eds) Microbial mats stromatolites: 101-119. Alan R. Liss, New York, New York, USA.

CASTENHOLZ RW (2001) Phylum BX Cyanobacteria. oxigenic photosynthetic bacteria. En: Boone DR, RW Castenholz \& GM Garrity (eds) Bergey's manual of systematic bacteriology. Volumen 1.The Archea and depply branching and photrophic bacteria: 473-599. Springer-Verlag, New York, New York, USA.

CAUMETTE P, R MATHERON, N RAYMOND \& JC RELEXANS (1994) Microbial mats in the hypersaline ponds of Mediterrean salterns (Salinsde-Giraud, France). FEMS Microbiology Ecology 13: 273-286.

CHONG G (1984) Die Salare in Nordchile - Geologie, Struktur und geochimie. Goetektonische Forschung 67: 1-146.

DE WIT R \& P CAUMETTE (1994) Diversity of and interactions among sulphur bacteria in microbial mats. En: Stal L \& P Caumette (eds) Microbial mats: structure, development and environmental significance: 377-392. Springer-Verlag, Berlin, Germany.

DE WIT R \& H VAN GEMERDEN (1990) Growth and metabolism of the purple sulphur bacterium Thiocapsa roseopersicina under combined light/ dark and oxic/anoxic regimens. Archives of Microbiology 154: 459-464.

ESTEVE I, M MARTÍNEZ-ALONSO, J MIR \& R GUERRERO (1992) Distribution, typology and structure of microbial mat communities in Spain: a preliminary study. Limnetica 8: 185-195.

FRÜND C \& Y COHEN (1992) Diurnal cycles of sulfate reduction under oxic conditions in cyanobacterial mats. Applied and Environmental Microbiology 58: 70-77.

GARCÉS I, G CHONG, P LÓPEZ \& L AUQUÉ (1998) Comportamiento geoquímico y mineralógico del Salar de Llamará (Chile): Origen de sus solutos y evolución de sus salmueras. Boletín de la Sociedad Chilena de Química 43: 417-433.
GIANI D, J SEELER, L GIANI \& WE KRUMBEIN (1989) Microbial mats and physicochemistry in a saltern in the bretagne (France) and in a laboratory scale saltern model. FEMS Microbiology Ecology 62: 151-162.

GROSJEAN M (1994) Paleohydrology of the Laguna Lejía (north Chilean Altiplano) and climatic implications for late-glacial times. Palaeogeography Palaeoclimatology \& Palaeoecology 109: 89-100.

GUERRERO M, A TADEO \& R DE WIT (1994) Environmental factors controlling the development of microbial mats in inland saline lakes; the granulometric composition of the sediments. En: Stal L \& P Caumette (eds) Microbial mats: structure, development and environmental significance: 85-90. Springer-Verlag, Berlin, Germany.

HABICHT K \& DE CANFIELD (1996) Sulfur isotope fractionation in modern microbial mats and the evolution of the sulfur cycle. Nature 382: 342-343.

HERBERT RA (1985) Development of mass blooms of phototrophic bacteria on sheltered beaches in Scapa Flow, Orkney Island. Proceedings of the Royal Society of Edinburgh B 87: 15-25.

HERBERT R \& D WELSH (1994) Establishment of phototrophic purple sulphur bacteria in microbial mat systems. En: Stal L \& P Caumette (eds) Microbial mats: structure, development and environmental significance: 51-60. SpringerVerlag, Berlin, Germany.

HOFMANN C (1942) Beiträge zur vegetation des Frabstreifen-Sandwatt. Kieler Meeresforsch 4: 785-105.

HOFMANN C (1949) Über die Durchlässigkeit dünner sandschichten für Licht. Planta 37: 48-56.

HOLT J \& N KRIEG (1994) Enrichment and Isolation. En: Gerhardt P, RGE Murray, WA Wood \& NR Krieg (eds) Methods for general and molecular bacteriology: 179-215. American Society for Microbiology, Washington, District of Columbia, USA.

HOLT J, N KRIEG, P SNEATH, J STALEY \& S WILLIAMS (eds) (1994) Bergey's manual of determinative bacteriology, Ninth edition, Group 10. Anoxygenic phototrophic bacteria: 353-376. Williams \& Wilkins, Baltimore, Maryland, USA.

HURLBERT SH, M LOPEZ \& JO KEITH (1984) Wilson's phalarope in central Andes and its interaction with Chilean flamingo. Revista Chilena de Historia Natural 57: 47-57.

IGARZÁBAL A (1991) Evaporitas cuaternarias de la Puna Argentina. En: Pueyo JJ (ed) Génesis de formaciones evaporíticas: modelos andinos e ibéricos: 333 274. Universidad de Barcelona, Barcelona, España.

IVERSON WP (1966) Growth of Desulfovibrio on the surface of agar media. Applied Microbiology 14: 529-534.

JORGENSEN BB \& DC NELSON (1988) Bacterial zonation, photosynthesis and spectral light distribution in hot spring microbial mats of Iceland. Microbial Ecology 16: 133-147.

KARSTEN U (1996) Growth and organic osmolytes of geographically different isolates of Microcoleus Chthonoplastes (Cyanobacteria) from benthic microbial mats: response to salinity change. Journal of Phicology 32: 501-506.

KÜHL M, C LASSEN \& BB JORGENSEN (1994) Optical properties of microbial mats: light measurements with fiber-optic microprobes. En: Stal L \& P Caumette (eds) Microbial mats: structure, development and environmental significance: 149166. Springer-Verlag, Berlín, Germany.

KÜHL M \& T FENCHEL (2000) Bio-optical characteristics and the vertical distribution of 
photosyntethic pigments and photosyntesis in an artificial cyanobacterial mat. Microbial Ecology 40: 94-103.

LÓPEZ PL, LF AUQUÉ, I GRACÉS \& G CHONG (1999) Características geoquímicas y pautas de evolución de las salmueras superficiales del Salar de Llamará, Chile. Revista Geológica de Chile 26: 89-108.

MARTÍNEZ-ALONSO M (1997) Estudio comparativo de los ecosistemas bentónicos estratificados de la zona mediterránea de la península Ibérica. Caracterización ecofisiológica de los tapetes microbianos del Delta del Ebro. Tesis de Doctorado, Universidad Autónoma de Barcelona, Barcelona, España. 391 pp

MIR J, M MARTÍNEZ-ALONSO, I ESTEVE \& R GUERRERO (1991) Vertical stratification and microbial assemblage of a microbial mat in the Ebro Delta (Spain). FEMS Microbiology Ecology 86: 59-68.

OLLIVIER B, P CAUMETTE, JL GARCIAA \& RA MAH (1994) Anaerobic bacteria from hypersaline environments. Microbiological Reviews 58: 27-38.

PALMISANO A, S CRONIN, E DÁMELIO, E MUÑOZ \& D DES MARAIS (1989) Distribution and survival of lipophilic pigments in a laminated microbial mat community near Guerrero Negro, Mexico. En: Cohen Y \& E Rosenberg (eds) Microbial mats, physiological ecology of benthic microbial communities: 138-152. American Society of Microbiology, Washington, District of Columbia, USA.

PRADO B, A DEL MORAL \& V CAMPOS (1993) Distribution and types of heterotrophyc halophilic flora from Salar de Atacama, Chile. Toxicological and Environmental Chemistry 38: 163-166.

RIPKA R, J DERUELLES, JB WATTERBURY, M HERDMAN \& RY STAINER (1979) Generic assignements, strain histories and properties of pure cultures of cyanobacteria. Journal of General Microbiology 111: 1-61.

RISACHER F \& B FRITZ (1991 a) Geochemistry of Bolivian salars, Lipez, southern Altiplano: origin of solutes and brine evolution. Geochimica et Cosmochimica Acta 55: 687-705.

RISACHER F \& B FRITZ (1991 b) Quaternary geochemical evolution of the salars of Uyuni and Coipasa, central Altiplano, Bolivia. Chemical Geology 90: 211-231.

ROUND FE, M CRAWFORD \& DG MANN (1990) The diatoms: morphology and biology of the genera.
Cambridge University Press, Cambridge, United Kingdom. 757 pp.

STAL L J, H VAN GENERDEN \& WE KRUMBEIN (1984) The simultaneous assay of chlorophyll and bacteriochlorophyll in natural microbial communities. Journal of Microbiological Methods 2: $295-306$

SERVANT-VILDARY \& SH MELLO-E-SOUSA (1993) Palaeohydrology of the quaternary saline lake Ballivian (southern Bolivian Altiplano) based on diatom studies. International Journal of Salt Lake Research 2: 69-95.

STOLZ JF \& L MARGULIS (1984) The stratified microbial community at Laguna Figueroa, Baja California, México; a posible model for prephanerozoic laminated microbial communities preserved in cherts. Origins of Life 14: 671-679.

TESKE A, N RAMSING, K HABICHT, M FUKUL, J KÜVER, B JORGEMNSEN \& Y COHEN (1998) Sulfate-reducing bacteria and their activities in cyanobacterial mats of Solar Lake (Sinai, Egypt). Applied and Environmental Microbiology 64: 29432951.

THOMAS JC (1984) Formations benthiques à cyanobactéries des salins de Santa Pola (Espagne): composition spécifique, morphologie et caractéristiques biologiques des principaux peuplements. Revista de Investigaciones Geológicas (España) 38/39: 139-158.

VAN DEN ENDE F, A LAVERMAN \& H GEMERDEN (1996) Coexistence of aerobic chemotrophic and anaerobic phototrophic sulfur bacteria under oxygen limitation. FEMS Microbiology Ecology 19: 141-151.

VAN GEMERDEN H, CS TUGHAN, R DE WIT \& RA HERBERT (1989) Laminated microbial ecosystems on sheltered beaches in Scapa Flow, Orkney Islands. FEMS Microbiology Ecology 62: 87-102.

ZÚÑIGA LR, V CAMPOS, H PINOCHET \& B PRADO (1991) A limnological reconnaissance of Lake Tebenquiche, Salar de Atacama, Chile. Hydrobiologia 210: 1-2.

ZÚÑIGA O, R WILSON, F AMAT \& F HONTORIA (1999) Distribution and characterization of chilean populations of the brine shrimp Artemia (Crustacea, Branchiopoda, Anostraca). International Journal of Salt Lake Research 8: 23-24. 